\title{
Institutional Culture and OER Policy: How Structure, Culture, and Agency Mediate OER Policy Potential in South African Universities
}

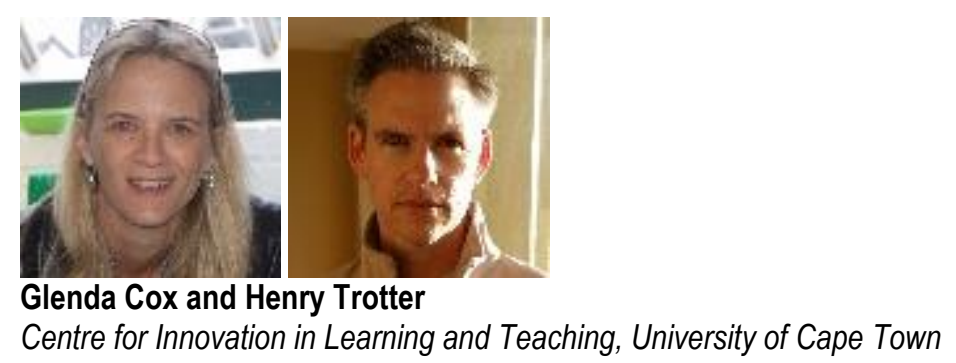

\begin{abstract}
Several scholars and organizations suggest that institutional policy is a key enabling factor for academics to contribute their teaching materials as open educational resources (OER). But given the diversity of institutions comprising the higher education sector-and the administrative and financial challenges facing many institutions in the Global South-it is not always clear which type of policy would work best in a given context. Some policies might act simply as a "hygienic" factor (a necessary but not sufficient variable in promoting OER activity) while others might act as a "motivating" factor (incentivizing OER activity either among individual academics or the institution as a whole).

In this paper, we argue that the key determination in whether a policy acts as a hygienic or motivating factor depends on the type of institutional culture into which it is embedded. This means that the success of a proposed OER-related policy intervention is mediated by an institution's existing policy structure, its prevailing social culture and academics' own agency (the three components of what we're calling "institutional culture"). Thus, understanding how structure, culture, and agency interact at an institution offers insights into how OER policy development could proceed there, if at all. Based on our research at three South African universities, each with their distinct institutional cultures, we explore which type of interventions might actually work best for motivating OER activity in these differing institutional contexts.
\end{abstract}

Keywords: open educational resources, OER, institutional culture, policy, structure, culture, agency, social realism, enabling factors, motivating factors 


\section{Introduction}

Several scholars suggest that institutional policy is a key enabling factor for academics to contribute their teaching materials as open educational resources (OER) (Browne et al., 2010; Carson, 2009; Corrall \& Pinfield, 2014; Janssen et al., 2014; Lee et al., 2008; Lesko, 2013; Reed, 2012). Based on a similar understanding, organizations such as UNESCO have put considerable support behind national-level OER policy initiatives and The Hewlett Foundation has funded multiple projects designed to write and enact OER-related policies. ${ }^{1}$

However, given the diversity of institutions comprising the higher education sector, it is not always clear which type of policy is best. For instance, should OER contribution by academics at a university be "mandated" or simply "encouraged?" Bliss (2014) argues for mandate-style policies that would require academics to "adopt"-use and create-OER as default practice. The potential of this approach can be seen at institutions that enjoy high levels of administrative and financial capacity to support such policy commitments-such as MIT (Abelson, 2008; Carson, 2009), which has opened up almost all of its course materials through its OpenCourseWare initiative (http://ocw.mit.edu)-and other types of institutions that have adopted an Open Access mandate (e.g., European Commission, CERN, World Bank, etc.). But would an OER mandate be appropriate at institutions where administrative and financial capacity is weak, as is often the case in the Global South?

Moreover, would a mandate work the same at an institution in which the academics (the creators) hold copyright over their own teaching materials versus an institution in which in the university (the employer) holds it?

These questions show that, while policy clearly plays an important "enabling" function in institutional OER activities, this does not help determine which type of policy would best be adopted at a particular institution. Following Herzberg (1987), some policies will act as a "hygienic" factor (a necessary but not sufficient variable in promoting OER activity) while others will act as a "motivating" factor (incentivizing OER activity either among individual academics or the institution as a whole).

We believe that the key determination in whether a policy acts as a hygienic or motivating factor depends on the type of institutional culture into which it is embedded. This means that the success of a proposed OER-related policy intervention is mediated by an institution's existing policy structure, its prevailing social culture and academics' own agency (the three components of what we're calling "institutional culture"). Thus, understanding how structure, culture, and agency interact at an institution offers insights into how OER policy development could proceed there, if at all.

In this paper, we explore the potential of OER-related policy interventions at three South African universities, each of which have quite different institutional cultures. We start by explaining the type of institutional culture that each exhibits, then examine the role that institutional policy and support mechanisms (structure), academic and disciplinary norms (culture), and individual academics' personal freedom to act on their desires (agency) have on OER-related policy interventions. We

${ }^{1}$ UNESCO, "Implementing the Paris OER Declaration: Components of the project":

http://www.unesco.org/new/en/communication-and-information/access-to-knowledge/open-educationalresources/implementing-the-paris-oer-declaration/components-of-the-project/; Hewlett, "Open Educational Resources": http://www.hewlett.org/programs/education/open-educational-resources; Commonwealth of Learning, "Taking OER beyond the OER Community: Policy and Capacity": http://oldwebsite.col.org/progServ/programmes/eLearning/Pages/oerpolicy.aspx 
conclude with recommendations on which type of interventions might actually work best for motivating OER activity in these differing institutional contexts.

\section{Conceptual Framework and Theoretical Perspective}

Our understanding of the concept of institutional culture comes from two approaches, both of which focus on academic organizations. McNay (1995) defines institutional culture types according an organization's relationship with its policies. That is, (a) how loose or tight its policy definitions are, and (b) how loose or tight its control of implementation is of those policies. McNay posits four institutional culture types:

1. Collegium ("laissez faire"): loose policy definition, loose control of implementation.

2. Bureaucracy: loose policy definition, tight control of implementation.

3. Enterprise: tight policy definition, loose control of implementation.

4. Corporation: tight policy definition, tight control of implementation.

This is a useful schema, but the term "culture" begs for a more expansive understanding than that offered by a narrow focus on institutional policy metrics. Hence, we also draw on the work of Bergquist and Pawlak (2008) which defines institutional culture types according to multiple variables, including governance style, level of members' personal autonomy and location of members (virtual/present). Six types of academic institutional cultures are proposed-collegial, managerial, developmental, advocacy, virtual, and tangible-though only the first two are relevant for us here:

1. Collegial: decentralized governance, academic freedom, faculty contributions.

2. Managerial: bureaucracy, hierarchical, efficiency and assessment of work.

Drawing on these two approaches, we have combined elements of them below with Margaret Archer's theory of social realism, which uses the concepts of structure, culture, and agency to help analyze decisions and activity in a given context. Essentially, we employ the notion of "institutional culture" as a broad descriptive term to help differentiate between complex institutional entities that are constituted by their dynamic interplay between structure, culture, and agency. How these three variables combine at any institution helps us determine what kind of institutional culture predominates there, allowing us to ask how OER-related policy interventions might perform there.

\section{Social Realism}

While some theoretical explanations have been suggested for why academics contribute OER (Harley, 2011; Hodgkinson-Williams \& Paskevicius, 2012; McAndrew, 2006; Pegler, 2012; Van Acker et al., 2013), there is still a gap in understanding exactly how these choices relate to institutional, socioeconomic, and policy factors. Hodgkinson-Williams and Gray (2009) use Archer's social realist theory to understand how national and institutional policy structures enabled or constrained lecturer practices at a South African university, a study that informs our approach here. 
Archer (2003) is essentially concerned with the question, "How does structure influence agency?" And, is there a process or causal mechanism that links the two? She argues that it is the properties and powers of agents that need to be considered. Structure impinges on agents to condition their actions through constraints and enablements that either impede or facilitate courses of action, therefore it is "only because people envisage a course of action can one speak of constraint and enablement" (2003, p.4).

Archer $(1996$; 2003) provides a number of tools in order to understand the relationship between culture/structure and agency, including the concepts of "analytic dualism" and "concerns" of agents. She starts by making an analytic distinction between agency and the structure and culture the individual exists within. This "structure" can be understood as the context and the "cultural setting" as a set of beliefs or ideas in which individuals find themselves. Archer uses "analytical dualism" to explore the interplay between them (Archer, 2003, p.71). Structural or cultural factors or both can be isolated (the context for actions of agents) and it becomes possible to tease out analytically how these factors shape the interactions of agents and how those interactions in turn maintain or change the initial context and/or beliefs.

Individuals are "active agents" who follow a trajectory which starts with their "concerns:" "those internal goods that they care most about." These concerns result in elaborating a "project" which, if it successfully addresses the concern, is "translated into a set of established practices" (Archer, 2007, p.42). An individual's sense of self comes from what really matters to them, what they choose to invest in. Individuals can exercise free will, however there are "degrees of freedom" that are constrained by the social structure (Archer, 2010, p.234; Archer, 2003, p.6).

\section{Methodology}

With the above in mind, the following discussion draws on interviews taken with academics at three South African universities: the University of Cape Town (UCT), the University of Fort Hare (UFH) and the University of South Africa (UNISA). In a national context of 25 public universities, these three institutions possess qualities that, in their different ways, mirror in a representative fashion the cumulative qualities of the other 22, which is useful for comparative purposes.

\section{Context}

First, local naming of university types is relevant. In South African usage, "traditional" universities offer degrees based on theoretical knowledge while "comprehensive" universities offer a combination of academic and vocational diplomas and degrees (Sedgwick, 2004).

UCT is a traditional, urban, residential, medium-sized (26,00o students), research-intensive university with a face-to-face teaching model. It is comparatively well-resourced, historically "white" (legally so during apartheid) and "privileged" (in South African parlance).

UFH is a traditional, rural, residential, small (13,000 students), teaching-intensive university with a face-to-face teaching model. It is comparatively poorly resourced, historically "black African" and "previously disadvantaged." 
UNISA is a comprehensive, dispersed, massive (400,000+ students), teaching-intensive university with a distance (correspondence) teaching model. It is comparatively well resourced, historically multi-racial, and modestly privileged.

\section{Process}

We started our research by conducting OER workshops at each university in March 2015. Each of the workshops had 12-19 participants and ran for a day-and-a-half, with the first day devoted to discussing the openness movement, the opportunities afforded by OER, and how to find OER online. The second day covered Creative Commons licensing, which, for most participants, was completely new information. In addition, we guided participants through a process of actually creating or adapting an OER to share.

Then we conducted one-on-one interviews with six local academics at each university, chosen mainly from the field of workshop participants. The interviews lasted between 30 minutes and one hour. Of the 18 people that we interviewed in total, eleven (61\%) were female and seven (39\%) were male; one was a professor, one was an associate professor, six were senior lecturers, six were lecturers, two were postgraduate students (and also instructors), and two were education consultants connected to a university. In addition, to broaden the data that we are drawing on for this paper, we have included the responses of 14 interviews carried out with academics at the University of Cape Town by Cox (2016) for her PhD research. Of these, half were women, three were professors, four were associate professors, five were senior lecturers, and two were lecturers.

\section{Institutional Culture}

Given the theoretical and methodological points above, we can now define the types of institutional cultures that exist at the three universities. These brief descriptions will be further substantiated throughout the rest of the paper, and will allow us to consider how OER-related policy interventions might fare there.

UCT has a collegial institutional culture (what McNay calls collegium), but not due so much to any loose policies. Indeed, it has modestly tight (coherent) policies that are also reasonably wellimplemented, but these policies happen to preserve the autonomy of the university's scholars who, themselves, engaged in the policy-development process to ensure this. So "collegial" in this sense is more in line with Bergquist and Pawlak's (2008) approach, which focuses on distributed power relations, faculty contribution, and academic freedom. However, the fact that the university has policies that support a collegial environment does not mean that they are what produced it. Quite the contrary: it was the pre-existing collegial culture that produced the policies which reinforce and protect it. Thus, any policy that hoped to increase OER engagement at the university would likely have to be aligned with these values to have any success (Czerniewicz \& Brown, 2015).

UFH has what we call a bureaucratic institutional culture (which aligns partly with McNay's notion of bureaucracy and Bergquist and Pawlak's managerial culture). This bureaucratic culture is characterized by a top-down power structure, where scholars are bounded by relatively copious policies and regulations which they experience not as contributing to a broader, well-defined vision or strategy, but as overwrought and unnecessary self-auditing. This reinforces the power of the bureaucratic strata because scholars must constantly assess their own activities and performance 
against official procedures. A number of our respondents called this a "tick the box" approach, wondering whether such procedurality had any value for their overall educational mission. In this environment, it would be challenging to insert an OER policy because scholars might view it as another bureaucratic imposition rather than a positive addition to their broader teaching and learning strategy.

Lastly, UNISA has a managerial institutional culture (or what McNay refers to as corporation). It has a hierarchical power structure, but its heavy rules and regulations contribute to a relatively clear institutional mission and vision. Scholars must comply with these tight policies, but doing so yields productive results because academics see how they contribute to the broader institutional strategy. This is not the same as bureaucratic entanglement, but rather compliance for the sake of coordinated achievement of the institution's unique distance education mission. In this environment, strong policy development is essential if academics are to engage with OER at any significant level.

\section{Structure}

This discussion of institutional culture types offers a starting point for exploring the more specific elements that shape these institutions: especially how structural, cultural, and agential variables impact each other and any proposed policy interventions. We will now look at the first element of Archer's concepts-structure-at each of the three universities so as to understand the role that institutional policy and support mechanisms play in OER (in)activity there.

But first, we must briefly discuss the national legal context regarding Intellectual Property (IP) rights, as this has a profound effect on the types of IP policies currently in force at South African universities. The key text, in this regard, is the Copyright Act of 1978 which grants certain types of employers copyright over certain outputs of their employees' work-product. Most South African universities interpret this to mean that the copyright of their academics' teaching materials is vested in the institution, not in the individual creator or creators. Even in cases where an institution confers copyright over teaching materials automatically to the academic creator, it does so with the implicit understanding that it is the default copyright-holder according to national legislation.

In line with this, most South African universities explicitly claim copyright over teaching materials produced by their academics. Indeed, of the 25 universities in the country, only five grant the creators of the materials copyright over their work (Trotter, 2016).

\section{University of Cape Town (UCT)}

In contrast to most other universities in the country, UCT academics are allowed to possess the copyright of their teaching materials and thus turn them into OER. As the UCT IP Policy states:

UCT automatically assigns to the author(s) the copyright. . . in. . course materials, with the provision that UCT retains a perpetual, royalty-free, nonexclusive licence to use, copy and adapt such materials within UCT for the purposes of teaching and or research. (UCT, 2011, p.15) 
The policy goes on to state that:

UCT supports the publication of materials under Creative Commons licences to promote the sharing of knowledge and the creation of Open Education Resources. UCT undertakes certain research projects that seek to publish the research output in terms of a Creative Commons licence. (UCT, 2011, p.15)

This opportunity is further reinforced by UCT's Open Access Policy, which promotes "the sharing of knowledge and the creation of open education resources" (UCT, 2014, p.3). It does not mandate that academics share their teaching and learning materials as OER, but simply encourages them to do so, as is befitting in a collegial cultural environment. This intention is additionally strengthened by the university's signing of the Cape Town Open Education Declaration and the Berlin Open Access Declaration (Czerniewicz, 2014).

Crucially, this policy-enshrined encouragement is supported by practical mechanisms to help academics engage in OER activities, such as the OpenUCT Institutional Repository for depositing one's teaching materials to share as OER (https://open.uct.ac.za/), the provision of OER grants by the Centre for Innovation in Learning and Teaching (CILT) for scholars who want to turn their teaching materials into OER (http://www.cilt.uct.ac.za/grants), the regular OER workshops and training sessions held by CILT and the legal advice scholars can obtain when licensing their materials as OER (http://ip-unit.org/).

In this context, where scholars enjoy positive policy, financial, technical, and legal support-and an inhouse repository to upload and share their OER-all of the structural elements necessary for engaging in OER activity are in place. However, as we will see below, UCT scholars do not view these institutional policies and support mechanisms as "motivating" factors for OER activity, but simply as hygienic factors creating the conditions necessary to allow them to act on their own personal volition regarding OER. Thus, in this instance, while we must acknowledge the important role that structure plays in enabling OER activity, we will have to look beyond it if we hope to understand what actually motivates UCT scholars to contribute OER.

\section{University of Fort Hare (UFH)}

In contrast to UCT, UFH academics do not have permission to share their teaching materials as they wish, because all of their work-product-including teaching materials-belongs to the university. As the UFH IP Policy states, "The University of Fort Hare claims ownership of all intellectual property devised, made, or created by persons employed by the University in the course of their employment," which includes "works generated by computer hardware or software owned or operated by the University" and "films, videos, multimedia works, typographical arrangements, field and laboratory notebooks, and other works created with the aid of University facilities" (UFH, 2010, p.5).

Thus they are constrained on the production side. However, on the usage side, "there's a certain degree of flexibility," as one academic said. Even though "we do get our curricula handed down to us pretty much," UFH scholars can incorporate some OER into their teaching so long as they meet the requirements of the relevant curriculum guidelines. 
But with the lack of policy support for OER activity-and no imminent strategy in development-there are also a lack of structural mechanisms to support it: no repository, no grants, no personnel, no training, no technical or legal support, etc. This means that policy currently acts as a "de-motivating" factor, if anything.

Furthermore, academics acknowledge their ambivalence regarding the potential of policy interventions (of any sort) in their institution, with some stating that these were more likely to reinforce a "tick the box" culture of "compliance"-characterized by an increased burden for academics to account for their activities - rather than a sincere buy-in or motivation for engaging with them. They did not believe that a policy-led approach would lead to sustainable OER activity, primarily because policy wasn't effectively enforced and because it would be useless without all of the other support mechanisms that are necessary to act on their OER interests.

Thus, in a bureaucratic institutional culture where academics feel that the current style of policy development and enforcement leads to ambivalent outcomes-where "they're normally there to monitor and constrain"-it is not surprising that some would prefer that policy not play a key role in spurring OER activity. As one scholar stated, "If there was a policy that there was no policy" or "if the policy was freedom of choice," then they would feel more interest in sharing OER because it would allow scholars to act on their own authentic interests, which is a more sustainable approach.

\section{University of South Africa (UNISA)}

UNISA academics bear the same restrictions as UFH scholars in terms of copyrighted work-product, with the UNISA IP Policy stating, "UNISA is the owner of all IP created by members of staff within the normal courses and scope of their employment" (UNISA, 2012, p.5). However, according to UNISA's OER Coordinator, academics may petition their relevant tuition committees to allow them to share their personally-created teaching materials as OER. None of our research participants or workshop attendees had heard of this option, so it does not appear to be well advertised (a point to which the OER Coordinator agreed), but it does offer an opening for OER contribution at an individual level.

Furthermore, it is technically possible for the curriculum guidelines and courseware production teams to incorporate OER into their work, though our respondents admitted that they often relied on traditional teaching practices with well-known published (copyrighted) textbooks and materials.

Additionally, not all students enjoy reliable access to computers or the internet, thus all teaching materials must be printable and deliverable through the post so that every student receives the same quality of education. Of course, some OER can be printed, but if academics want to use it digitally (the optimal medium for many OER, such as videos), these can only be offered as "additional" and "optional" materials.

However, while this IP policy might typically deter OER activities among academics-as it does at UFH-the university itself has stated an ambition to contribute the institution's course materials as OER. According to the UNISA OER Strategy, "OER cannot be considered as marginal, socially acceptable, nice-to-have activities. They must be integrated into mainstream institutional processes if we wish to harness the true potential of OER in our transformation process and if the shift to this paradigm is to be economically and practically sustainable" (UNISA, 2014, p.4). Hence, the management has developed a comprehensive strategic approach to incorporate external OER into 
UNISA courses and share internally developed course materials and components as OER. This must still be operationalized and encoded in formal policy, but the Strategy suggests that the moral and philosophical commitment to openness may eventually lead to concrete policies, mechanisms, and actions.

This means that, though the IP policy reduces the latitude academics have in personally sharing their materials as OER, the university itself, as the copyright owner of those "assets" (as they are called in the Strategy), can license and share it as OER. While the academics will have created the teaching materials that end up being shared, their personal volition regarding sharing becomes less relevant as their work-product is incorporated into a broader, institutional OER ambition.

In this context-in which a progressive leadership, capacitated by a strong managerial culture, leverages its rights over academics' teaching materials according to the IP policy-structure plays the key role in determining OER activity. Policy acts as the primary motivating factor, not necessarily for the academic "creators" of the materials, but for the institutional "owners" who are able to take advantage of the opportunity that this ownership provides in extending UNISA's mission, value, and brand.

Furthermore, the university has committed financial, intellectual, and technical resources to this ambition. It established the position of OER Coordinator in the Office of the Pro Vice-Chancellor, initiated a series of workshops and training sessions to increase academics' OER literacy, signed the Paris OER Declaration and the Berlin Open Access Declaration, and formalized a collaboration with the OER Universitas (OERu) as a founding anchor partner (UNISA, 2014).

Most of the scholars we interviewed believed that, while the heavy use of policies and regulations at UNISA could sometimes be a burden, they ultimately saw the value of such policy coherence in their unique context as a massive distance learning provider. As one academic shared, "policy is good and I think policy can be a motivating factor," but it just must fit "within a very strategic place within the organization architecture."

Based on the insights above, we can see how policy impacts OER activity in different institutional culture contexts for both academics and the institutional leadership. In UCT's collegial environment, policy is a hygienic factor that enables, but does not motivate, OER activity among the academics. In UFH's bureaucratic context, the closed IP policy does not enable or motivate academics to engage with OER. It rather enables the university (as the copyright owner of the teaching materials) to do so. But because the administration has not elaborated a strategy to share its teaching materials openly, the IP policy does not motivate it to act in this regard. It views its IP assets (teaching materials) as something to be protected and controlled rather than opened and shared. Lastly, in UNISA's managerial context, academics are neither enabled nor motivated to contribute OER in any significant capacity. However, the IP policy does enable the management to share the university's teaching materials as OER, and it motivates it to do so as well because the OER Strategy elaborates a desire to act on the opportunity that this ownership provides over a vast collection of IP assets. Thus, in this setting, policy acts as both a hygienic and motivating factor for OER engagement by the management. 


\section{Culture}

While South African scholarly attitudes and behaviour are certainly shaped by the institutional policy structures in which they are situated, they are also impacted by the social, departmental, and disciplinary norms and expectations, or "culture," that defines their workspace and networks. That is, beyond policy and governance issues, academics occupy a social world among peers-their typical reference groups for judging their own actions-who may exert diverse forces on them regarding whether they should share their materials with their colleagues (or openly with the public), whether they should develop their own teaching materials from scratch (or incorporate open materials into them as well) and so forth. In some institutional culture contexts, this often ends up being the space in which the motivation for their activities derives.

AT UCT, culture is comparatively more important than policy in motivating academics' engagement with OER. The behaviour and judgment of peers acts as a powerful mechanism in shaping academics' own beliefs and pursuits. This is especially true with regard to research activities where scholars face significant pressure from colleagues to contribute a steady string of peer-reviewed publications to their field - this is part of UCT's "ethos" (Trotter et al., 2014, p.85). The same cannot be said, however, regarding OER activity where there is very little pressure to contribute. This fact partially explains the relatively low levels of OER contribution at the university. (For instance, in the OpenUCT Institutional Repository \{http://open.uct.ac.za/\}-which hosts open access research outputs and OER-only 65 of the 11,953 items in it are tagged as "teaching and learning resources" at the time of writing.)

Indeed, when asked "How does the culture of your department influence your decisions around OER use and creation?" one UCT scholar stated that, in her Humanities circles:

you'll find there's a lot of resistance to certain technologies. We really feel that face-to-face is important. We find the lecture space very important. We find the relationships that we build with students to be incredibly important for learning. And anything that takes place at that distance is going to encounter a fair amount of resistance, I think, as a kind of a cultural thing within [my discipline].

Hence, disciplinary teaching strategies, which may rely on face-to-face engagement rather digitallymediated materials development, can lead some academics to operate in a pedagogical space where OER contribution is not really practical or relevant.

At UFH, departmental and disciplinary norms are highly important, because in the absence of a coherent institutional policy structure, they provide academics with useful guidelines-steeped in tradition or corroborated by trusted peers-for the particular practices that they engage in. Lacking clear institutional directives regarding initiatives such as OER, UFH scholars say that it would be important for a "critical mass of adopters" to embrace it if they were to do the same. It gives the activity legitimacy even if it is not officially supported by the administration. As one scholar noted when asked how the culture of his department influenced his OER decisions, he stated, "If I was surrounded by adopters of OER, I would certainly be more creative in my use of same." 
However, since the IP policy bars most OER activity for scholars, we must approach the question of engagement hypothetically. When asked "Could creating and sharing OER potentially change your institution's practice?” one UFH scholar replied:

Theoretically yes, [there is] is there a possibility to change the way things are done, most definitely. Gaining critical mass changes mission critical approaches to teaching, but the reality is I don't really think that there are enough staff with that-not just the ability, but the inclination to fiddle. There's a massive fear in terms of new technologies. I think that simple technological things will be tricky, but there also isn't a culture of sharing, because there is a cultural fear around who's seeing what I'm doing and criticism and so on. There are pockets where people are sharing a lot with each other, but on the whole I think there's [not much].

This suggests that culture is a lynchpin which, if changed, could overcome institutional inertia and low levels of individual agency. But at the moment, there is not a culture of sharing which would be essential for broad OER adoption.

At UNISA, departmental and disciplinary culture is less important than institutional policy, but likely more important than individual agency in shaping a response to OER. That is because of the way in which courses are designed and taught, with high levels of collaboration and coordination between the academics in the process. With courses that often have more than a thousand students enrolled in them, most are overseen by multiple academics who would have created, selected, and vetted the teaching materials as a group. Thus decisions around OER use within their courses (and potential OER contribution, for later potential distribution by the university) are usually made corporately, relying on a good deal of negotiation and consensus between them. Nevertheless, this process remains quite dependent on the desires set out by the leadership. As one scholar shared, "the department won't really do anything until they get a proper directive or policy or something from the management."

This discussion alerts us to the role that culture might play in determining the success, or lack thereof, of an OER-related policy intervention. Where there is a culture of sharing already (at least in pockets), it is unlikely that a policy will do much to provide extra motivation, as at UCT. Where culture acts a guide for academic activity due to a lack of institutional policy clarity and low levels of personal agency, the incorporation of a positive OER-related policy would at least allow peers to feel legally empowered to engage OER, potentially mobilizing a "critical mass" which would re-shape the institution's practices, such as at UFH. And where culture is subservient to institutional structure in determining academics' behaviour, as at UNISA, culture would only have a mild impact on OER activities.

\section{Agency}

Lastly, to understand how an OER-related policy intervention would work at a particular institution, we need to grasp the role of academics' agency in determining its reception.

At UCT, the role of agency is paramount in scholars' OER activity. Indeed, most scholars suggest that the OER-friendly policies that exist at the university do not act as a motivating factor for OER 
adoption, but are merely a hygienic factor. They create the conditions necessary for OER contribution, giving them the legal freedom to share their teaching materials as OER, but they state that this fact, in and of itself, does not motivate them to actually do so. It is, or would be, their ultimate concerns which include internal moral and educational philosophies that drive them to make such efforts.

In fact, because many UCT scholars did not know about or understand the ramifications of these policies, when asked about whether "policy" (in the abstract) would motivate their OER adoption, current OER contributors felt that policy would negatively impinge on their activities, while noncontributors felt that it would not make any difference to them. As one OER contributor stated, "I think [a policy] could become coercive...I do not think I would be as willing to share if it was a policy sort of thing. ..." Another said, "I might share more, but I would share anyway." This same academic was also worried about the potential effect any sort of mandatory policy would have on contribution, "I am concerned that if it became a top down instruction. . . one of those things that has to be done, [it] might perhaps also generate some negativity around it." This suggests that some academics might simply resist such a mandate, as one scholar stated, "I am very rarely governed by any policies."

These expressions of caution and skepticism in the face of hypothetical policy interventions reinforce the image that, in a collegial institutional culture such as UCT, the motivation for actual engagement with OER will likely come from the individual academics themselves. As one scholar explained:

I have a lot of autonomy. So I guess if I were under the thumb of an old-fashioned head of department I probably wouldn't be allowed to do [OER work], but I can essentially do whatever I want with my time, as long as the things that need to be done get done. And so everyone's been very supportive, but it was primarily because [my colleague] and I saw the [OER] grant and we said, 'This is awesome, let's do it,' and no one stood in our way.

Indeed, these are the kinds of stories around OER most heard at UCT, in which an academic with a belief in open educational practices took advantage of the available institutional support and contributed an OER.

At UFH, there is stronger role for policy to play with regard to OER, if only because the current IP policy disallows academics from sharing their work openly. Of course, if the university had a desire to turn its IP assets into OER, then the IP policy would not be the obstacle, but rather the lack of strategy to harness it. But it has neither, which leaves the university unable to capitalize on its IP assets and academics unable to contribute their materials as OER. This compromises the agency scholars have with their teaching resources.

Our UFH interviewees did not claim to have high levels of autonomy, regardless of the IP policy. They described having to contend with fairly heavy bureaucratic and procedural mechanisms which took up a lot of their time, and to which they were somewhat resigned. Thus any sort of OER-related policy intervention would be appreciated-in the abstract-but without institutional support mechanisms and without a critical mass of adopters to help spread the load of the OER learning curve, it would act as an "enabling" factor in the weakest possible sense. This recognition shows how interdependent the notion of "agency" is with "structure:" without enough of the latter, there's not much of the former. 
Lastly, UNISA scholars also reveal low levels of personal agency, a factor that would typically impact their ability to engage with OER. But in this case, because the university has taken a leadership role in harnessing the institution's IP assets for a broader OER mission, the academics' agency is not the critical factor in whether OER activity will occur at UNISA. If the OER Strategy ever becomes an OER Policy, then the academics' work and agency will be co-opted by the management for this new open imperative. This is not to say that the administration has gone ahead without any consultation with the academics (though many did not know anything about the university's OER ambitions), because it is now trying to build up scholars' OER literacy and capacity so that they can better prepare their materials for a time when OER is normalized within the curriculum (de Hart, Chetty \& Archer, 2015). Thus, as noted above, policy in this environment is crucial because it is the axis around so much of the academics' activities turn.

\section{Discussion}

With the above in mind, it is evident that any discussion of a policy intervention must start with an appreciation of the institutional cultures into which it would fit. This caveat does not obviate the need for some form of appropriate policy to exist for OER activity to proceed at an institution, but it suggests that a number of other factors may in fact have a greater impact on motivating academics to use or contribute OER than policy.

In Table 1, we try to capture the key variables for motivating OER activities according to the three institutional culture profiles we have discussed above. It shows the relative importance of structure, culture and agency in shaping academics' behaviour, and offers, in conjunction with what we know about existing OER-related policies at these institutions, whether a policy intervention would offer the best strategy for motivating academics' contribution of OER or whether some other strategy might be more effective.

Table 1

The Relative Importance (Low, Medium, High) of Structure, Culture, and Agency on Motivating OER Activities According to Institutional Culture Context

\begin{tabular}{|l|c|c|c|}
\hline Institutional Culture & $\underline{\text { Structure }}$ & Culture & Agency \\
type & institutional policies & social/disciplinary norms & personal motivation \\
\hline Collegial (UCT) & low & medium & high \\
\hline Bureaucratic (UFH) & medium & high & low \\
\hline Managerial (UNISA) & high & medium & low \\
\hline
\end{tabular}


Thus, at UCT with its collegial institutional culture, academics enjoy high levels of agency in which their motivation to engage with OER derives from their individual concerns, such as their personal educational philosophy or sense of openness. These motivations are mildly shaped by departmental and disciplinary norms and only minimally by the positive OER-related policies and support mechanisms available to them. In this environment, it is doubtful whether any further policy elaboration would create higher levels of motivation regarding OER. The most sustainable strategy appears to be the one that it has already adopted, allowing OER activity to develop organically, in fits and starts, with non-coercive institutional support.

At UFH, academics lack even the basic hygienic factors necessary for OER engagement, thus it is difficult to talk about what would act as motivating factors in anything but hypothetical terms. In this respect, a policy intervention allowing scholars to possess copyright of their teaching materials would be a useful first step in moving towards a situation where they could leverage the cultural power of their peer groups to engage with OER. But if we see the IP policy not as an obstacle but an opportunity for the management, similar to UNISA, then the intervention would have to come at the level of strategy, in encouraging the administration to treat its IP assets as something worth sharing openly. However, it is difficult to develop and implement tight, coherent strategies in a bureaucratic institutional culture due, in part, to the fact that a lot of administrative activity is focused on operational compliance rather than strategic engagement. Therefore, any recommendation for an OER policy or strategy intervention in this environment would have to remain aware of the challenges surrounding the sustainability of such an initiative.

Lastly, at UNISA, the university's managerial institutional culture makes an OER-related policy intervention the appropriate type of instrument for spurring OER activity there. High-level policy is the tool by which new initiatives are best instituted, creating the highest likelihood of sustainable commitment over time. Of course, in this particular case, the necessary policy and strategy are already in place. It is now just a matter of allowing the management to gradually operationalize its OER ambitions, moving from strategic declaration to policy implementation.

\section{Conclusion}

This paper argues that policy, whether in the form of a hard mandate or soft encouragement, should not be conceived of, ipso facto, as a "motivating factor" for OER activity because each university's institutional culture mediates the role that policy plays in academics' decision making. This means that, while every university may need an appropriate IP policy to allow academics or the university to engage with OER, the presence of this policy may have no motivating impact on actual OER activity. In such a case, the IP policy would be a hygienic rather than a motivating factor.

This distinction matters because both factors are ultimately required for an institution to enjoy a sustainable engagement with OER. And knowing this means that OER advocates, from the individual proponent up to the intergovernmental organization, must take a nuanced, tailored and often multipronged approach to OER interventions at different institutions. This may be especially true for those in the Global South where there is not only a high degree of organizational diversity, but challengingly low levels of administrative and financial support. 


\section{Acknowledgments}

The authors would like to thank Kerry de Hart at the University of South Africa and Renée Coetzee at the University of Fort Hare for their assistance with our research efforts at their institutions. We would also like to thank Cheryl Hodgkinson-Williams and Michelle Willmers of the Research on Open Educational Resources for Development (ROER4D) project for their valuable feedback on this article. We also extend the same gratitude to the two IRRODL reviewers of this paper. The research analyzed here emerges from our work with ROER4D and was carried out with the aid of a grant from the International Development Research Centre (IDRC), Ottawa, Canada.

\section{References}

Abelson, H. (2008). The creation of OpenCourseWare at MIT. Journal of Science Education and Technology, 17(2), 164-174.

Archer, M. S. (1996). Culture and agency: The place of culture in social theory. 2nd edition. Cambridge: Cambridge University Press.

Archer, M. S. (2003). Structure, agency, and the internal conversation. Cambridge: Cambridge University Press.

Archer, M. S. (2007). Making our way through the world: Human reflexivity and social mobility. Cambridge: Cambridge University Press.

Archer, M. S. (2010). Morphogenesis versus structuration: On combining structure and action. The British Journal of Sociology, 61, 225-253.

Bergquist, W. H. \& Pawlak, K. (2008). Engaging the six cultures of the academy: Revised and expanded edition of The Four Cultures of the Academy. San Francisco: Jossey-Bass.

Bliss, T. J. (2014, November 11). Musings on OER policy [Blog post]. Retrieved from http://tjbliss.org/musings-on-oer-policy/

Browne, T., Holding, R., Howell, A. \& Rodway-Dyer, S. (2010). The challenges of OER to academic practice. Journal of Interactive Media in Education, 3. Retrieved from http://jime.open.ac.uk/article/download/2010-3/399/

Carson, S. (2009). The unwalled garden: Growth of the OpenCourseWare Consortium, 2001-2008. Open Learning: The Journal of Open, Distance and e-Learning, 24(1), 23-29.

Corrall, S. \& Pinfield, S. (2014). Coherence of "open" initiatives in higher education and research: Framing a policy agenda. Proceedings of the iConference, 2014 (pp 293-313). Berlin, 3-7 March 2014. Retrieved from http://hdl.handle.net/2142/47316 
Cox, G. (2016). Explaining the relation between culture, structure and agency in lecturers' contribution or non-contribution to Open Educational Resources in Higher Education. Unpublished PhD thesis. University of Cape Town, South Africa. Available: http://hdl.handle.net/11427/20300

Czerniewicz, L. (2014, June 18). UCT's open access policy: A culmination and a beginning [Blog post]. Retrieved from http://openuct.uct.ac.za/blog/uct-open-access-policy-culmination-andbeginning

Czerniewicz, L. \& Brown, C. (2009). A study of the relationship between institutional policy, organisational culture and elearning use in four South African universities. Computers \& Education, 53(1), 1-19.

de Hart, K., Chetty, Y., \& Archer, E. (2015). Uptake of OER by staff in distance education in South Africa. International Review of Research in Open and Distributed Learning, 16(2), 18-45. Retrieved from http://www.irrodl.org/index.php/irrodl/article/view/2047

Harley, K. (2011). Insights from the Health OER Inter-institutional Project. Distance Education, 32(2), 213-227.

Herzberg, F. (1987). One more time: How do you motivate employees? Harvard Business Review, 65(5), 109-120.

Hodgkinson-Williams, C. \& Gray, E. (2009). Degrees of openness: The emergence of open educational resources at the University of Cape Town. International Journal of Education and Development using Information and Communication Technology, 5(5). Retrieved from http://open.uct.ac.za/bitstream/handle/11427/8860/CHED_article_OERemergence_Hodgk insonWilliams 2009.pdf?sequence $=1$

Hodgkinson-Williams, C. \& Paskevicius, M. (2012). The role of postgraduate students in co-authoring open educational resources to promote social inclusion: A case study at the University of Cape Town. Distance Education, 33(2), 253-269.

Janssen, B., Jelgerhuis, H. \& Schuwer, R. (2014, April 24). Supporting open education policymaking by higher education institutions in The Netherlands: Lessons learned. Paper presented at OpenCourseWare Consortium Global 2014: Open Education for a Multicultural World, Ljubljana, Slovenia. Retrieved from http://cdlh7.free.fr/OCWC_2014/Final_papers/Paper_37.pdf

Lee, M. Y., Albright, S., O’Leary, L., Terkla, D. G. \& Wilson, N. (2008). Expanding the reach of health sciences education and empowering others: The OpenCourseWare initiative at Tufts University. Medical Teacher, 30(2), 159-163.

Lesko, I. (2013). The use and production of OER \& OCW in teaching in South African higher education institutions [Case Study]. Open Praxis, 5(2). Retrieved from http://openpraxis.org/index.php/OpenPraxis/article/view/52 
McAndrew, P. (2006). Motivations for OpenLearn: The Open University's open content initiative, commissioned report for OECD. Milton Keynes: Open University. Retrieved from http://www.oecd.org/edu/ceri/38149250.pdf

McNay, I. (1995). From collegial academy to corporate enterprise: The changing cultures of universities. In T. Schuller (Ed.), The Changing University? (pp. 105-115). Buckingham, UK: Society for Research into Higher Education and Open University Press.

Pegler, C. (2012). Herzberg, hygiene and the motivation to reuse: Towards a three-factor theory to explain motivation to share and use OER. Journal of Interactive Media in Education, 2012(1). Retrieved from http://doi.org/10.5334/2012-04

Reed, P. (2012). Awareness, attitudes and participation of teaching staff towards the open content movement in one university. Research in Learning Technology, 20. Retrieved from http://dx.doi.org/10.3402/rlt.v20io.18520

Sedgewick, R. (2004, May 1). Institutions of higher education in South Africa after the mergers. WENR. Retrieved from http://wenr.wes.org/2004/05/wenr-mayjune-2004-institutions-ofhigher-education-in-south-africa-after-the-mergers/

Trotter, H., Kell, C., Willmers, M., Gray, E. \& King, T. (2014). Seeking impact and visibility: Scholarly communication in Southern Africa (Cape Town: African Minds). Retrieved from http://openuct.uct.ac.za/sites/default/files/media/SCAP_Synthesis_Report_WEB.pdf

Trotter, H. (2016, June 1). How Intellectual Property (IP) Policies affect OER Creation at South African Universities [Blog post]. Retrieved from http://roer4d.org/2298

UCT (University of Cape Town) (2011). University of Cape Town Intellectual Property Policy. Retrieved from http://www.uct.ac.za/downloads/uct.ac.za/about/policies/intellect property.pdf

UCT (2014). University of Cape Town Open Access Policy. Retrieved from https://www.uct.ac.za/downloads/uct.ac.za/about/policies/UCTOpenAccessPolicy.pdf

UFH (University of Fort Hare) (2010). University of Fort Hare Policy on Intellectual Property. Retrieved from http://ufhgmrdc.ac.za/portals/gmrdc/downloads/policydownloads/ippolicyfinalsenateappro ved2june10.pdf

UNISA (University of South Africa) (2012). UNISA Intellectual Property Policy. Retrieved from http://www.unisa.ac.za/research/news/wpcontent/uploads/2014/06/IP Policy app Council 2 22.06.2012.pdf

UNISA (2014). UNISA Open Educational Resources (OER) Strategy 2014-2016. Retrieved from http://www.unisa.ac.za/contents/unisaopen/docs/OER\%20Strategy\%20(final)\%20March\%2 02014.pdf 
Van Acker, F., Van Duuren, H., Kreijns, K. \& Vermeulen, M. (2013). Why teachers share educational resources: A social exchange perspective. In R. McGreal, W. Kinuthia \& S. Marshall (Eds.). Open Educational Resources: Innovation, Research and Practice (pp.177-192). Athabasca, Canada: Commonwealth of Learning.

\section{Athabasca}

University

(c) (1) 